\title{
ANALISIS REGRESI LOGISTIK ORDINAL FAKTOR-FAKTOR YANG MEMPENGARUHI STATUS BEASISWA MAHASISWA DI UNIVERSITAS MATARAM
}

\author{
Ordinal Logistic Regression Analysis of Factors Affecting Students' \\ Scholarship Status in Mataram University
}

\author{
Baiq Rika Ayu Febrilia ${ }^{1 *}$, Mi'rojatul Handa Yani', Syahril Anwar ${ }^{3}$ \\ 1,2,3 Prodi Pendidikan Matematika, FSTT, Universitas Pendidikan Mandalika \\ Jl. Pemuda No. 59A, Mataram, 83125, Indonesia
}

e-mail:1*rikafebrilia@ikipmataram.ac.id ; ${ }^{2}$ mirojatulhandayani@gmail.com ; 3 anwarhaerel@gmail.com Corresponding Author*

\begin{abstract}
Abstrak
Penelitian ini bertujuan untuk menganalisis faktor-faktor yang mempengaruhi status beasiswa mahasiswa (mendapat atau tidak mendapat beasiswa) menggunakan analisis regresi logistik ordinal. Subjek yang terlibat sebanyak 100 orang mahasiswa di Universitas Mataram. Penelitian menggunakan data primer yang dikumpulkan melalui lembar survei online. Variabel penelitian adalah status beasiswa mahasiswa sebagai variabel respon dan jalur masuk ke perguruan tinggi negeri, jenis pekerjaan orang tua, status Kartu Indonesia Pintar (KIP) sebagai variabel prediktornya. Masing-masing variabel dibagi menjadi beberapa kategori dalam skala ordinal, sehingga regresi logistik ordinal menjadi solusi dalam menjelaskan hubungan antar variabel tersebut. Hasil penelitian menunjukkan bahwa faktor-faktor yang mempengaruhi status beasiswa mahasiswa adalah jalur masuk perguruan tinggi dan jenis pekerjaan orang tua. Hubungan dari ketiga variabel ini diberikan oleh satu model logit.
\end{abstract}

Kata Kunci : regresi logistik ordinal, faktor-faktor, status beasiswa.

\begin{abstract}
This study aims to analyze the factors that influence the status of student scholarships (get or not get a scholarship) using ordinal logistic regression analysis. The subjects involved were 100 students at Mataram University. The data used in this study are primary data collected using the Google Form online survey sheet. The research variable is the status of student scholarships as a response variable and entry path to state universities, the type of parent's occupation, the status of the Indonesia Smart Card (KIP) as its predictor variable. Each variable is divided into several categories on an ordinal scale, so that ordinal logistic regression is a solution in explaining the relationship between these variables. The results showed that the factors influencing the status of student scholarships were college entry channels and the type of parent's occupation. The relationship of these three variables is given by one logit model.
\end{abstract}

Keywords: ordinal logistic regression, factors, scholarship status. 


\section{PENDAHULUAN}

Beasiswa adalah salah satu program yang dikembangkan dalam rangka membantu siswa atau mahasiswa mengatasi masalah keuangan dalam melanjutkan studinya. Mahasiswa yang mendapatkan beasiswa akan terbantu dari sisi ekonominya karena biasanya urusan biaya kampus dan kebutuhan sehari-hari telah termasuk dalam hitungan beasiswa. Terlebih saat ini biaya yang dibutuhkan untuk dapat menyelesaikan studi pada tingkat perguruan tinggi sangat besar, sedangkan kemampuan orang tua untuk mendukung pendanaan cukup rendah. Hal ini menyebabkan banyak mahasiswa yang tergiur untuk mendapatkan beasiswa. Akan tetapi, menjadi mahasiswa penerima beasiswa dalam Perguruan Tinggi tertentu bukanlah hal yang mudah karena mereka harus memenuhi syarat-syarat yang dikehendaki dan berani berkompetisi dengan mahasiswa-mahasiswa lain yang tidak kalah dalam kompetensi dan kesempatan untuk mendapatkan beasiswa tersebut.

Dalam mengajukan beasiswa, terdapat berbagai poin informasi yang harus mahasiswa laporkan, seperti pekerjaan orang tua [1][2][3]. Bahkan pada jenis beasiswa tertentu, pekerjaan orang tua juga menjadi salah satu bagian penting atau dapat dikatakan sebagai faktor penting yang mempengaruhi seseorang layak atau tidak dalam mendapatkan beasiswa. Sebagai contoh pada Beasiswa Bidik Misi, sebagian besar mahasiswa penerima beasiswa berasal dari orang tua dengan latar belakang pekerjaan menengah ke bawah [4][5]. Selain jenis pekerjaan orang tua, faktor lain yang mungkin berpengaruh adalah ada atau tidaknya Kartu Indonesia Pintar (KIP) yang dimiliki oleh mahasiswa. Bukti kepemilikan KIP ini juga menjadi salah satu dokumen penting yang harus dilampirkan oleh mahasiswa calon penerima beasiswa dengan ekonomi kurang, sehingga KIP juga berpengaruh dalam menentukan seorang mahasiswa untuk mendapatkan beasiswa. Faktor lainnya yang mungkin juga berpengaruh adalah jalur masuk mahasiswa pada perguruan tinggi negeri. Hal ini karena poin penilaian untuk setiap jalur masuk berbeda-beda, sehingga dimungkinkan mempengaruhi perbedaan input yang pada akhirnya bermuara pada adanya motivasi mahasiswa untuk mendapatkan beasiswa atau tidak. Sebagai contoh, pada penelitian [6], mahasiswa dengan jalur masuk tertentu lebih mendominasi kuota beasiswa bidik misi pada perguruan tinggi lokasi penelitiannya. Oleh karena jenis jalur masuk Perguruan Tinggi, pekerjaan orang tua dan kepemilikan KIP secara teori cukup mempengaruhi seseorang mahasiswa dalam menerima atau tidaknya beasiswa, maka perlu dianalisis lebih jauh hubungan sebab akibat antara keempat variabel ini.

Salah satu analisis yang dapat digunakan dalam menganalisis suatu hubungan sebab-akibat antara variabel respon dan prediktor adalah analisis regresi [7]. Dengan kata lain, analisis regresi dapat mengulas mengenai faktorfaktor yang mempengaruhi adanya kondisi tertentu [8]. Analisis regresi terdiri atas beberapa jenis dan karakteristik data yang akan diteliti merupakan kunci utama dalam menentukan analisis regresi mana yang digunakan. Dalam penelitian ini, variabel-variabel yang akan dianalisis memiliki skala ordinal atau yang terdiri atas beberapa tingkatan kategori. Oleh karena itu, analisis regresi yang sesuai untuk kondisi variabel ini adalah analisis regresi logistik ordinal [9][10]. Peneliti seperti [11][12] telah menggunakan regresi logistik ordinal dalam menganalisis data yang menggunakan skala ordinal. Akan tetapi, keduanya tidak meneliti mengenai hubungan antara status beasiswa mahasiswa dengan jalur masuk perguruan tinggi, pekerjaan orang tua dan kepemilikian KIP. Di sisi lain, penelitian mengenai status beasiswa lebih menekankan kepada algoritma dalam menentukan mahasiswa mana yang akan menjadi penerima beasiswa berdasarkan pada pekerjaan orang tua dan faktor lainnya [2][3]. Peneliti tersebut tidak menjelaskan hubungan sebab akibat antar variabel tersebut.

Berdasarkan uraian yang telah dipaparkan, maka yang menjadi tujuan dari penelitian ini adalah untuk menganalisis faktor-faktor yang mempengaruhi status beasiswa mahasiswa pada suatu Perguruan Tinggi negeri melalui penggunaan analisis regresi logistik. Faktor-faktor yang dimaksud difokuskan pada jenis jalur masuk mahasiswa, pekerjaan orang tua dan kepemilikan KIP.

\section{METODELOGI PENELITIAN}

Bagian ini menjelaskan mengenai jenis penelitian, subjek, teknik yang digunakan dalam mengumpulkan data, variabel dan langkah penelitian.

\subsection{Jenis Penelitian}

Penelitian ini merupakan penelitian kuantitatif. Penelitian kuantitatif merupakan penentuan dengan data yang berbentuk angka atau bilangan agar dapat diolah atau dianalisa dalam perhitungan matematika. 


\subsection{Subjek Penelitian}

Subjek yang terlibat dalam penelitian ini adalah 100 orang mahasiswa di Universitas Mataram. Mahasiswa yang menjadi sampel dipilih secara acak.

\subsection{Teknik Pengumpulan Data}

Sumber data berasal dari data primer yang mana setiap sampel diminta untuk mengisi lembar survei online yang dikembangkan menggunakan aplikasi Google Form. Data tersebut berupa kumpulan pertanyaan mengenai informasi pribadi sampel khususnya yang berkaitan dengan apakah sampel mendapatkan beasiswa, jenis pekerjaan orang tua, jalur masuk perguruan tinggi dan kepemilikan Kartu Indonesia Pintar (KIP) serta beberapa pertanyaan lain yang mendukung penelitian.

\subsection{Variabel Penelitian}

Variabel-variabel yang digunakan dalam penelitian ini terdiri atas variabel respon dan variabel prediktor. Penjelasan mengenai masing-masing variabel ini beserta kategorinya adalah sebagai berikut.

Variabel respon atau yang biasa dinotasikan sebagai variabel $Y$ merupakan variabel mengenai status beasiswa mahasiswa yang terbagi menjadi dua kategori, yaitu

1. Menerima Beasiswa/Ya $\left(Y_{1}\right)$

2. Tidak Menerima Beasiswa/Tidak $\left(Y_{2}\right)$.

Variabel prediktor yang digunakan dalam penelitian dibagi menjadi tiga, yaitu variabel jalur masuk, pekerjaan orang tua dan Kartu Indonesia Pintar (KIP). Masing-masing variabel memiliki kategori sebagai berikut.

a. Variabel $X_{1}$ atau variabel jalur masuk memiliki 3 kategori, yaitu :

1. Seleksi Nasional Masuk Perguruan Tinggi Negeri (SNMPTN) $\left(X_{1,1}\right)$

2. Seleksi Bersama Masuk Perguruan Tinggi Negeri (SBMPTN) $\left(X_{1,2}\right)$

3. Mandiri $\left(X_{1,3}\right)$

b. Variabel $X_{2}$ atau variabel pekerjaan orang tua dengan 2 kategori, yaitu :

1. Pegawai Negeri Sipil (PNS)

2. Non-PNS

c. Variabel $X_{3}$ atau variabel Kartu Indonesia Pintar (KIP) dengan 2 kategori, yaitu :

1. Memiliki KIP

2. Tidak Memiliki KIP

\subsection{Langkah Penelitian}

Analisis data dan pengujian hipotesis model regresi logistik ordinal dilakukan dengan bantuan salah satu software statistika. Setelah hasil analisis keluar pada lembar output, maka langkah-langkah yang dikerjakan berikutnya adalah sebagai berikut.

1. Membuat tabel tabulasi karakteristik variabel $Y$ berdasarkan setiap variabel $X$ nya.

2. Membaca dan menyimpulkan hasil uji kecocokan model regresi logistik ordinal menggunakan Deviance dengan panduan hipotesis $\mathrm{H}_{0}$ : model cocok, $\mathrm{H}_{1}$ : model tidak cocok. Kesimpulan diambil dengan membandingkan taraf signifikan $(\alpha=0,05)$ yang digunakan dengan nilai taraf signifikansi atau $p$-value dari hasil pengujian. Apabila nilai $p$-value hasil pengujian lebih dari nilai $p$-value yang digunakan $(0,05)$ maka keputusan yang diambil adalah menerima $\mathrm{H}_{0}$. Apabila yang terjadi sebaliknya, maka keputusan yang diambil juga sebaliknya.

3. Membaca dan menyimpulkan hasil uji serentak model status beasiswa mahasiswa menggunakan Likelihood Ratio dengan mengacu pada hipotesis $H_{0}: \varphi_{1}=\varphi_{2}=\varphi_{3}=0$ dan $H_{1}$ : Minimal ada satu $\varphi_{j} \neq 0, \mathrm{j}=1,2,3$ [13]. Nilai $\varphi$ adalah nilai dari koefisien model yang diperiksa secara menyeluruh. Pengambilan kesimpulan sama dengan poin nomor 2.

4. Membaca dan menyimpulkan hasil uji parsial model regresi logistik ordinal menggunakan uji Wald dengan mengacu pada hipotesis $H_{0}: \varphi_{k}=0$ dan $H_{1}: \varphi_{k} \neq 0, \mathrm{k}=1,2,3$. Nilai $\mathrm{k}$ adalah banyaknya prediktor dalam model, sedangkan nilai $\varphi$ adalah nilai dari setiap parameter pada model [12]. Pengambilan kesimpulan sama dengan poin nomor 2 . 
5. Membuat model logit. Model logit dari regresi logistik ordinal mengikuti bentuk berikut.

$$
\operatorname{logit}(P[Y \leq k|x|])=\varphi_{0 k}+\sum_{p=1}^{q} \varphi_{p} x_{i p}
$$

di mana $Y$ adalah variabel respon, $x_{i}$ adalah vektor dari variabel prediktor $p, k$ adalah kategori dari variabel $Y$ dengan $k=1,2, \ldots, K-1$ dan $\varphi$ adalah vektor dari koefisien regresi.

\section{HASIL DAN PEMBAHASAN}

Ringkasan mengenai karakteristik dari variabel Y berdasarkan pada setiap variabel X disajikan pada Tabel 1, 2 dan 3. Secara umum ketiga tabel ini merupakan hasil analisis deskriptif dari data yang telah dikumpulkan.

Tabel 1. Karakteristik Y berdasarkan $X_{1}$

\begin{tabular}{|cccc|}
\hline \multirow{2}{*}{$\mathbf{X}_{\mathbf{1}}$} & \multicolumn{3}{c|}{$\mathbf{Y}$} \\
\cline { 2 - 4 } & Ya & Tidak & Total \\
\hline SNMPTN & $18(72 \%)$ & $7(28 \%)$ & $25(100 \%)$ \\
SBMPTN & $13(42 \%)$ & $18(58 \%)$ & $31(100 \%)$ \\
Mandiri & $9(20 \%)$ & $35(80 \%)$ & $44(100 \%)$ \\
\hline
\end{tabular}

Berdasarkan Tabel 1 diperoleh informasi bahwa mahasiswa yang masuk ke perguruan tinggi melalui jalur Mandiri lebih banyak tidak mendapatkan beasiswa yaitu sebanyak 35 dari 44 orang yang masuk melalui jalur ini, sedangkan kuantitas mahasiswa terbanyak yang mendapatkan beasiswa adalah mahasiswa yang masuk melalui jalur SNMPTN yaitu 18 dari 25 orang.

Tabel 2. Karakteristik $Y$ berdasarkan $X_{2}$

\begin{tabular}{|cccc|}
\hline \multirow{2}{*}{$\mathbf{X}_{2}$} & \multicolumn{3}{c|}{$\mathbf{Y}$} \\
\cline { 2 - 4 } & Ya & Tidak & Total \\
\hline $\boldsymbol{P N S}$ & $5(29 \%)$ & $12(71 \%)$ & $17(100 \%)$ \\
NON-PNS & $42(51 \%)$ & $41(49 \%)$ & $83(100 \%)$ \\
\hline
\end{tabular}

Tabel 2 menyajikan informasi mengenai sebaran penerima beasiswa dari mahasiswa yang orang tuanya bekerja sebagai PNS dan non PNS. Berdasarkan data tersebut diketahui bahwa pada mahasiswa yang orang tuanya tidak bekerja sebagai PNS, sebaran mahasiswa yang menerima dan tidak menerima beasiswa hampir sama. Banyaknya mahasiswa yang mendapat beasiswa dengan latar belakang orang tua non PNS ini 8 kali lipat lebih dari banyaknya mahasiswa yang mendapat beasiswa dengan latar belakang orang tua PNS.

Tabel 3. Karakteristik $Y$ berdasarkan $\mathrm{X}_{3}$

\begin{tabular}{|cccc|}
\hline \multirow{2}{*}{$\mathbf{X}_{\mathbf{3}}$} & \multicolumn{3}{c|}{$\mathbf{Y}$} \\
\cline { 2 - 4 } & $\mathbf{Y a}$ & Tidak & Total \\
\hline $\boldsymbol{K} \boldsymbol{I P}$ & $13(62 \%)$ & $8(38 \%)$ & $21(100 \%)$ \\
$\boldsymbol{N O N}-\boldsymbol{K I P}$ & $33(42 \%)$ & $46(58 \%)$ & $79(100 \%)$ \\
\hline
\end{tabular}

Berkaitan dengan kepemilikan KIP (Tabel 3), mahasiswa yang memiliki KIP lebih banyak mendapatkan beasiswa dari pada tidak mendapatkan beasiswa (13 dari 21 orang mahasiswa). Untuk mahasiswa non KIP, lebih banyak dari mereka adalah mahasiswa yang tidak menerima beasiswa (44 dari 79 mahasiswa). Penjelasan berikutnya adalah penjelasan mengenai hasil uji kecocokan model yang diberikan oleh Tabel 4. 
Tabel 4. Uji kecocokan model menggunakan Deviance

\begin{tabular}{|ccccc|}
\hline & Chi-Square & df & p-value & Keputusan \\
\hline Deviance & 5,367 & 5 & 0,373 & $\mathrm{H}_{0}$ diterima \\
\hline
\end{tabular}

Nilai $p$-value dari Deviance pada Tabel 4 menunjukkan bahwa nilai tersebut melebihi dari taraf signifikansi yang menjadi acuan, yaitu 0,05 . Dengan demikian, keputusan yang diambil adalah menerima $\mathrm{H}_{0}$ atau sesuai dengan hipotesis yang menjadi dasar (telah diuraikan pada bagian metodelogi) maka model yang diuji telah cocok.

Tabel 5. Uji serentak model menggunakan Likelihood Ratio

\begin{tabular}{|cccccc|}
\hline Model & $\mathbf{G}^{\mathbf{2}}$ & Chi-square & Df & p value & Keputusan \\
\hline $\begin{array}{c}\text { Intercept only } \\
\text { Final }\end{array}$ & 52,582 & & & & \\
\hline
\end{tabular}

Hasil uji serentak model yang diberikan pada Tabel 5 menunjukkan bahwa nilai $p$-value hasil pengujian yang sama dengan 0,00 bernilai kurang dari 0,05 . Oleh karena itu keputusan yang diambil adalah menolak $\mathrm{H}_{0}$ atau artinya terdapat minimal satu parameter yang signifikan. Hasil ini juga sesuai dengan kesimpulan yang diambil dengan memperhatikan nilai $G^{2}$. Nilai tersebut lebih besar dari nilai $\chi_{0,05 ; 4}^{2}=9,488$, sehingga dapat disimpulkan $\mathrm{H}_{0}$ ditolak. Oleh karena itu perlu adanya pengujian secara parsial.

Tabel 6. Hasil estimasi parameter model regresi logistik ordinal

\begin{tabular}{|cccccc|}
\hline Variabel & Kategori & Koefisien & Eror Standar dari Koefisien & Exp $(\varphi)$ & $p$-value \\
\hline Beasiswa $(\boldsymbol{Y})$ & Konstanta & $-1,098$ & 0,384 & & 0,004 \\
Jalur Masuk $\left(\boldsymbol{X}_{\mathbf{1}}\right)$ & SNMPTN & $-2,701$ & 0,670 & 0,067 & 0,018 \\
& SBMPTN & $-1,239$ & 0,525 & 0,290 & 0,018 \\
& Mandiri & 0 & $\cdot$ & $\cdot$ & $\cdot$ \\
Pekerjaan Orang Tua $\left(\boldsymbol{X}_{\mathbf{2}}\right)$ & PNS & 1,795 & 0,764 & 6,019 & 0,016 \\
& NON-PNS & 0 & $\cdot$ & $\cdot$ & $\cdot$ \\
Kartu Indonesia Pintar $\left(\boldsymbol{X}_{\mathbf{3}}\right)$ & KIP & $-0,685$ & 0,560 & 0,504 & 0,222 \\
& NON-KIP & 0 &. &. &. \\
\hline
\end{tabular}

Pengujian secara parsial (Tabel 6) menunjukkan beberapa koefisien variabel memiliki nilai $p$-value kurang dari 0,05 dan sebagian tidak. Koefisien variabel prediktor yang memiliki nilai $p$-value kurang dari 0,05 adalah $X_{1,1}, X_{1,2}$ dan $X_{2,1}$. Koefisien variabel inilah yang membangun model logit. Tabel 6 juga menunjukkan bahwa model logit yang terbentuk dari hasil analisis ini hanya satu model logit. Hal ini karena variabel respon terdiri atas dua kategori, sehingga terdapat satu model logit yang dihasilkan. Model logit tersebut adalah sebagai berikut.

$$
\operatorname{logit}(y)=\log \left(\frac{y}{1-y}\right)=-1,098+(-2,701) X_{1,1}+(-1,239) X_{1,2}+(1,795) X_{2,1}
$$

Model logit ini menunjukkan bahwa hanya dua faktor yang mempengaruhi status beasiswa mahasiswa di Universitas Mataram, yaitu jalur masuk dan pekerjaan orang tua. Melalui hasil analisis ini ditunjukkan pula bahwa KIP tidak berpengaruh secara signifikan. Interpretasi dari model di atas merujuk pada nilai $\operatorname{Exp}(\varphi)$ yang diberikan pada Tabel 6 . Nilai tersebut juga disebut sebagai nilai odds ratio. Untuk koefisien dari $X_{1,1}$ dan $X_{1,2}$, berdasarkan Tabel 6, diperoleh bahwa nilai $\operatorname{Exp}(-2,701)=0,067$, sedangkan $\operatorname{Exp}(-1,239)=0,290$. Hal ini menunjukkan bahwa mahasiswa di salah satu PTN di Kota Mataram yang masuk melalui jalur SBMPTN memiliki peluang mendapatkan beasiswa lebih besar dibandingkan yang masuk melalui jalur SNMPTN. 


\section{KESIMPULAN}

Berdasarkan pemaparan dari hasil penelitian maka dapat disimpulkan bahwa faktor-faktor yang mempengaruhi status beasiswa mahasiswa di Universitas Mataram adalah jalur masuk mahasiswa dan pekerjaan orang tua, sedangkan faktor lainnya tidak berpengaruh secara signifikan. Hasil analisis ini menghasilkan satu model logit yang menunjukkan hubungan antara ketiga variabel tersebut.

\section{DAFTAR PUSTAKA}

[1] I. Sayekti, "Pengujian Model Jaringan Syaraf Tiruan untuk Kualifikasi Calon Mahasiswa Baru Program Bidik Misi," JTET (Jurnal Tek. Elektro Ter., vol. 2, no. 1, pp. 55-60, April 2013.

[2] A. Musthafa, H. Suyono, and M. Sarosa, "Perbandingan Kinerja Algoritma C . 45 dan AHP-TOPSIS sebagai Pendukung Keputusan Proses Seleksi Penerima Beasiswa," J. EECCIS, vol. 9, no. 2, pp. 109-114, Desember 2015.

[3] M. A. Rahman, "Algoritma C45 untuk Menentukan Mahasiswa Penerima Beasiswa (Studi Kasus : PPS IAIN Raden Intan Bandar Lampung)," J. Teknol. Inf. Magister Darmajaya, vol. 1, no. 02, pp. 118-128, Oktober 2015.

[4] B. Arifin, Sulistyarini, and H. Syahrudin, "Penggunaan Beasiswa Bidik Misi pada Mahasiswa FKIP UNTAN," J. Pendidik. dan Pembelajaran Khatulistiwa, vol. 2, no. 12, Desember 2013.

[5] A. A. Rohman and S. U. M. Widjaja, "Analisis Perilaku Konsumtif dan Perilaku Menabung Mahasiswa Penerima Beasiswa Bidikmisi di Jurusan Ekonomi Pembangunan Fakultas Ekonomi Universitas Negeri Malang Angkatan 2014,” J. Pendidik. Ekon., vol. 11, no. 2, pp. 107-117, Oktober 2018.

[6] D. Handayani, Gustati, and D. M. Rissi, "Analisis Prestasi Akademik Mahasiswa Jurusan Akuntansi Politeknik Negeri Padang Berdasarkan Jalur Masuk," J. Politek. Caltex Riau, vol. 12, no. 2, pp. 105-114, November 2019.

[7] S. Imaslihkah, M. Ratna, and V. Ratnasari, "Analisis regresi logistik ordinal terhadap faktor-faktor yang mempengaruhi predikat kelulusan mahasiswa S1 di ITS Surabaya," J. Sains dan Seni Pomits ISSN 2337-3520 (2301-928X Print), vol. 2, no. 2, pp. 177-182, Agustus 2013.

[8] B. R. A. Febrilia, S. Rahayu, and B. D. Korida, "Ordinal Logistic Regression Analysis of Factors Affecting the Length of Student Study," J. Mat. "MANTIK," vol. 5, no. 1, pp. 28-34, Mei 2019.

[9] E. M. Sahetapy, Y. A. Lesnussa, and V. Y. I. Ilwaru, "Analisis Tingkat Pengetahuan Remaja Tentang Perilaku Merokok di Kota Denpasar,” BAREKENG J. Ilmu Mat. dan Terap., vol. 1, no. 1, pp. 73-83, Maret 2015.

[10] M. W. Talakua, A. Ratuanak, and V. Y. I. Ilwaru, "Analisis regresi logistik ordinal terhadap faktor-faktor yang mempengaruhi waktu kelulusan mahasiswa S1 di FMIPA Unpatti Ambon tahun 2016 dan 2017," BAREKENG J. Ilmu Mat. dan Terap., vol. 13, no. 1, pp. 033-038, Maret 2019.

[11] M. Nusrang, R. Bakri, A. S. Ahmad, and Asfar, "Analisis Regresi Logistik Ordinal Terhadap Faktor-Faktor yang Mempengaruhi Predikat Kelulusan Mahasiswa S1 Universitas Negeri Makasar," in Prosiding Seminar Nasional Lembaga Penelitian UNM, 2017, vol. 2, no. 1, pp. 655-661.

[12] A. Z. Wattimena, M. W. Talakua, and V. Temartenan, "Pemodelan Tingkat Kepuasaan Masyarakat Terhadap Proses Pelayanan Pembuatan Surat Izin Mengemudi di Satlantas Polres Ambon Menggunakan Regresi Logistik Ordinal," BAREKENG J. Ilmu Mat. dan Terap., vol. 11, no. 2, pp. 85-94, Desember 2017.

[13] T. Pentury, S. N. Aulele, and R. Wattimena, "Analisis Regresi Logistik Ordinal," BAREKENG J. Ilmu Mat. dan Terap., vol. 10, no. 1, pp. 55-60, Maret 2016. 